\title{
Gianfranco Pistoia: Battery Operated Devices and Systems
}

\author{
Elsevier, Amsterdam, 2009, VII+392 p., 167.94 €; ISBN: 978-0-444-53214-5
}

\author{
Rudolf Holze
}

Received: 3 January 2011 /Accepted: 3 January 2011 / Published online: 29 January 2011

(C) Springer-Verlag 2011

Presumably, there are more books devoted to primary and secondary batteries of all kinds and the associated electronics, power management systems, and material science than there are on the actual applications, i.e., the numerous devices running on these batteries, and the many places where primary or secondary batteries are indispensable. At first glance, this unbalanced situation seems to be justified: Whatever progress battery researcher and developer will make is heartily welcome to all customers, and given the multiple choices, it is their task to find the most suitable system.

From the researcher's point of view, a detailed knowledge of the numerous places and applications the products of their research and development will finally end up and may, nevertheless, be more helpful than initially assumed: When considering the properties of a particular battery or accumulator component with respect to general improvement or better adaptation to a particular use, some knowledge about this use, going beyond the most basic facts, may turn out to be very helpful. The present book by an expert known for his numerous contributions in the fields of intrinsically conducting polymers and materials for secondary lithium batteries provides exactly this help. Already the first pages are sort of an enlightening. The reviewer cannot remember having seen before such well-organized lists of possible/already established applications in alphabetical and in topological order. Quite obviously, the author is drawing from a rich source of own scientific work and prodigious publicationslike the book "Lithium Batteries" he published for the first

R. Holze $(\bowtie)$

Technische Universität Chemnitz, Institut für Chemie,

Straße der Nationen 62,

09111 Chemnitz, Germany

e-mail: Rudolf.holze@chemie.tu-chemnitz.de time, when the current development and bright future was far from sure - in 1994, and for a second time, in 2004.

Following the listings already mentioned, battery categories and types are briefly reviewed, quite reasonably, the author limits himself to the essentials and the most salient features, and no competition with the numerous books on primary and secondary batteries is intended. A few general remarks on strong and weak points of aqueous primary batteries, as frequently encountered in portable applications, are added.

Chapter III deals with all kinds (some presumably hardly known to the general public) of portable devices. Industrial devices (not necessarily mobile or even portable, but definitely battery-operated) are carefully discussed in much detail in chapter IV, and the final chapter is devoted to applications in vehicles covering all aspects from traction batteries over batteries for control systems to basics of electric vehicles. An extensive list of acronyms provides relief to readers of publications sometimes spiced with rather unpopular abbreviations.

The book is enriched with numerous figures and pictures (with a collection of instructive colored photographs placed as an appendix not even mentioned in the table of contents). They are always very instructive, and only very infrequently their quality is somewhat poor (low resolution, shades of gray) making detection of details difficult. Fortunately, this affects mostly pictures of a fairly generic character (e.g., p. 344 , photograph of a plug-in hybrid car, p. 346, power control unit). The book is a must for every library associated with research and development groups working on electrochemical energy conversion and storage. Unfortunately, its price is not conducive for placing it in the desktop library of the active researcher.

Rudolf Holze

Chemnitz 